\title{
OPEN In-house reverse transcriptase polymerase chain reaction for detection of SARS-CoV-2 with increased sensitivity
}

\begin{abstract}
Manash Jyoti Kalita ${ }^{1,5}$, Kalpajit Dutta ${ }^{1,5}$, Gautam Hazarika ${ }^{1}$, Ridip Dutta ${ }^{3}$, Simanta Kalita ${ }^{1,2}$, Partha Pratim Das ${ }^{1,2}$, Manash P. Sarma ${ }^{4}$, Sofia Banu ${ }^{1}$, Md. Ghaznavi Idris ${ }^{1}$, Anjan Jyoti Talukdar ${ }^{2}$, Sangitanjan Dutta ${ }^{2}$, Ajanta Sharma ${ }^{3 凶}$ \& Subhash Medhi $^{1 凶}$

As the COVID-19 infection continues to ravage the world, the advent of an efficient as well as the economization of the existing RT-PCR based detection assay essentially can become a blessing in these testing times and significantly help in the management of the pandemic. This study demonstrated an innovative and rapid corroboration of COVID-19 test based on innovative multiplex PCR. An assessment of optimal PCR conditions to simultaneously amplify the SARS-CoV-2 genes E, $S$ and RdRp has been made by fast-conventional and HRM coupled multiplex real-time PCR using the same sets of primers. All variables of practical value were studied by amplifying known targetsequences from ten-fold dilutions of archived positive samples of COVID-19 disease. The multiplexing with newly designed $\mathrm{E}, \mathrm{S}$ and RdRp primers have shown an efficient amplification of the target region of SARS-CoV-2. A distinct amplification was observed in $37 \mathrm{~min}$ using thermal cycler while it took 96 min in HRM coupled real time detection using SYBR green over a wide range of template concentrations. Our findings revealed decent concordance with other commercially available detection kits. This fast HRM coupled multiplex real-time PCR with SYBR green approach offers rapid and sensitive detection of SARS-CoV-2 in a cost-effective manner apart from the added advantage of primer compatibility for use in conventional multiplex PCR. The highly reproducible novel approach can propel extended applicability for developing sustainable commercial product besides providing relief to a resource limited setting.
\end{abstract}

The sudden outbreak of an acute respiratory syndrome of an unknown etiology among the population of Wuhan city in China in the month of December, 2019, appeared to be something novel in nature. In the beginning, the outbreak was presumed to have originated from a seafood market located in the vicinity of Wuhan city. Eventually, it was discovered that the causal agent of the infection was a Beta-coronavirus related to previously known members of the family of SARS and MERS. Initial reports indicated that SARS-CoV-2 was more distant from the previously known SARS-CoV and MERS-CoV than the two bat-derived SARS-like coronaviruses bat-SLCoVZC45 (87.9\% sequence identity) and bat-SL-CoVZXC21 (87.2\% sequence identity). The virus belongs to the family Coronaviridae and order Nidovirales and has immense ability to mutate and undergo recombination ${ }^{1-5}$. SARS-CoV-2 belongs to the genus $\beta$-coronavirus which is comprised of crown-like, enveloped, positive-sense single-stranded RNA viruses. The genome sequence length of SARS-CoV-2 is about $30 \mathrm{~kb}$, with a $5^{\prime}$-cap structure and 3 '-poly-(A) tail enveloped by a complex of structural proteins to form a crown-like enveloped virus ${ }^{1,6,7}$. The novel 2019-nCoV caused an outbreak with a lower respiratory tract disease called novel coronavirus pneumonia (NCP), and lead to a large-scale epidemic in a short time that immediately received worldwide attention. Subsequently, 2019-nCoV was renamed as SARS-CoV-2 by the International Committee on Taxonomy of Viruses and Disease and the disease as COVID-19.

\footnotetext{
${ }^{1}$ Laboratory of Molecular Virology and Oncology, Department of Bioengineering and Technology, Gauhati University, Guwahati, Assam 781014, India. 'Department of Medicine, GMCH, Guwahati, Assam 781032, India. ${ }^{3}$ Department of Microbiology, GMCH, Guwahati, Assam 781032, India. ${ }^{4}$ Department of Biotechnology, Assam Down Town University, Guwahati, Assam 781068, India. ${ }^{5}$ These authors contributed equally: Manash Jyoti Kalita and Kalpajit Dutta. ${ }^{\circledR}$ email: ajantasharma2002@yahoo.com; subhashmedhi@gauhati.ac.in
} 
Polymerase Chain Reaction (PCR) is a gold standard technique which offers significant advantages in viral detection and quantification with high reproducibility and sensitivity ${ }^{9}$. Initially, for the detection of COVID-19, a reliable qRT-PCR assay was developed by the Centers for Disease Control and Prevention (CDC), USA. With time, various laboratories across the world developed different primer/probe pairs for specific detection of SARSCoV-2 with varying sensitivity and accuracy. However, in at least three independent studies it was reported that the primer pairs suggested for $\mathrm{N}$ region by US CDC, namely 2019-nCoV_N2 showed significant background cross reactivity $^{10}$, along with non-specific amplification. Another primer $2019-n C o V \_N 3$ has been reported to give false negative result ${ }^{11}$ in a study that includes SARS-CoV-2 positive patients besides showing false positive result even in the absence of template ${ }^{10}$. Similarly the most preferable primer RdRp-P2, used in more than 30 European laboratories has been reported to have less sensitivity ${ }^{12}$.

With the surge in disease burden, the demand for rapid screening for SARS-CoV-2 has risen significantly. Undeniably, the present circumstances have driven the need for more specific and sensitive primers for virus detection without false-positive results. We performed literature review of articles via selecting keywords 'RTPCR detection of COVID-19', 'primer specificity of SARS-CoV-2 detection assay', 'sensitivity and specificity of COVID-19 detection test' with probable sensitivity limit or limit of detection (LoD) that are reported based on the analysis. Upon reviewing and analysing the primer pairs that are initially prescribed by different public health agencies, we observed a noticeable difference in detection sensitivity at lower template concentrations besides producing the false-positive results. Such limitations simultaneously drive the need for the availability of more specific primer/probes that can accurately detect COVID-19 cases in robust conditions. Moreover, the establishment of non-hazardous infrastructure encompassing skilled manpower, availability of reagent subsequently increases the per sample cost that appears to be an additional burden for any country with resource constraints.

In the current scenario, rapid and accurate detection of SARS-CoV-2 could significantly influence the management of the pandemic. World Health Organization (WHO) guideline require, at least two different targets on the COVID-19 virus genome for the detection of SARS-CoV-2 through PCR amplification. This study has therefore focused on developing a Fast Multiplex Polymerase Chain Reaction targeting E, S and RdRp gene of SARS-CoV-2, detectable through Agarose gel-based visualization besides HRM coupled multiplex Real-Time PCR based validation using the same primer set. The optimized PCR condition applied for both the traditional method and HRM coupled multiplex Real Time PCR along with the adoption of the sample pooling strategy in the present study established a more sensitive assay protocol with reduced cost.

\section{Materials and method}

Sample collection. Archived positive samples of a varied range of $\mathrm{C}_{t}$ values ranging from low to high $\mathrm{C}_{t}$ value (Tested using Standard Operating Procedure from ICMR-NIV Pune which uses Invitrogen SuperScript III Platinum One-Step Quantitative Kit) were collected from State Level Viral Research and Diagnostics Laboratory (VRDL), Gauhati Medical College and Hospital were used as in the study. A total of 100 known positive and 33 known negative samples were included in the study.

Viral RNA extraction. Viral RNA extraction was carried out using AuPreP Viral RNA Extraction Miniprep System (Life technologies, Cat no: RNV-52-906LT) following the manufacturer's protocol. The extracted RNA was then quantified using Nano Drop Spectrophotometer (NanoVue plus, Make: Invitrogen) and the values recorded in $\mathrm{ng} / \mu \mathrm{l}$. The extracted RNA was converted into cDNA immediately.

Reverse transcription. Tetro cDNA Synthesis Kit (Make: Meridian Bioscience, Cat. No: BIO-65043) was used for cDNA preparation using the manufacturer's protocol. $5 \mu \mathrm{g}$ of the extracted RNA was used for cDNA preparation in a final volume of $20 \mathrm{\mu l}$ reaction. Each reaction was incubated at $25^{\circ} \mathrm{C}$ for $10 \mathrm{~min}$ followed by $45^{\circ} \mathrm{C}$ for $30 \mathrm{~min}$ and finally terminated by incubating at $85^{\circ} \mathrm{C}$ for $5 \mathrm{~min}$.

Primer design. The full sequences of SARS-CoV-2 were retrieved from the NCBI Reference Sequence Database. Alignment of the sequences was done in BioEdit software. Primer3 tool (https://bioinfo.ut.ee/primer3-0. 4.0/) was used to design the three primer sets targeting the SARS-CoV-2 specific E gene, $S$ gene and RdRp gene. The selected primer pairs were analyzed using NCBI primer blast for the specificity of the primer set. Blast report showed that all the three primers have specifically amplified the target region of SARS-CoV- 2 only. The primers pairs were further analyzed for secondary structure, the amplicons as well as probable self and heterodimer formation tendencies using Idtdna.com (https://sg.idtdna.com/pages/tools/oligoanalyzer). The primer sets were synthesized and delivered by Reprocell Brand: Bioserve (Hyderabad, Telangana. India).

Primer testing and development of fast PCR assay. The accuracy and optimization of each primer set was verified through PCR amplification. Gradient PCR of the test was performed with an annealing temperature profile ranging from 62 to $68^{\circ} \mathrm{C}$ based on the melting temperature $\left(\mathrm{T}_{\mathrm{m}}\right)$ of each of the SARS-CoV-2 specific target primer set. The template concentration was kept up to a maximum of $10 \mathrm{ng}$ of cDNA in a reaction volume of $20 \mu \mathrm{l}$ along with forward and reverse primer sets at a final concentration of $0.2-0.3 \mu \mathrm{M}$ each using Emerald Amp GT PCR Master Mix (2x) from Takara Bio Inc. (Cat No. RR310A). The cycling condition includes an initial denaturation step at $95^{\circ} \mathrm{C}$ for $5 \mathrm{~min}$. Amplification was carried out for 35 cycles with denaturation at $95^{\circ} \mathrm{C}$ for $20 \mathrm{~s}$, followed by a temperature gradient of $62-68^{\circ} \mathrm{C}$ for $30 \mathrm{~s}$ to obtain the optimum annealing temperatures, and extension at $72{ }^{\circ} \mathrm{C}$ for $20 \mathrm{~s}$. A final extension was carried out at $72^{\circ} \mathrm{C}$ for $7 \mathrm{~min}$.

Following primer optimization, the cycling condition was modified by reducing the denaturation time to $5 \mathrm{~s}$ and eliminating the extension step at $72^{\circ} \mathrm{C}$ for $20 \mathrm{~s}$. As such the Fast PCR assay will involve an initial denaturation 
at $95{ }^{\circ} \mathrm{C}$ for $5 \mathrm{~min}$. Amplification will be done by denaturation at $95^{\circ} \mathrm{C}$ for $5 \mathrm{~s}$, followed by annealing at $66^{\circ} \mathrm{C}$ for $15 \mathrm{~s}$ and extension at $72{ }^{\circ} \mathrm{C}$ for $5 \mathrm{~min}$.

Fast multiplex PCR amplification of E, S and RdRp gene. To minimize the amount of sample and reagent usage, preparation time, cost and labor, we developed an alternative protocol by adopting a multiplex PCR protocol for detection of SARS-CoV-2 in which all the primer sets were mixed into one reaction which reduced the total number of reactions to 1 (one) per sample instead of 3 (three) reactions. When mixed, the final concentration of the primer pairs was reduced proportionally to decrease primer- dimer formation. The designed primer pairs targeting the E, S and RdRP genes in the SARS-CoV-2 genome, produced amplicons of different sizes (i.e., $101 \mathrm{bp}, 103 \mathrm{bp}$, and $160 \mathrm{bp}$, respectively) for easy separation and visualization. The Applied Biosystems Veriti 96-Well Thermal Cycler instrument was used for multiplex PCR. EmeraldAmp GT PCR Master Mix (Cat No: RR310A) was used and each $20 \mu \mathrm{l}$ reaction mixture contained $10 \mu \mathrm{l}$ of PCR Master Mix $0.5 \mu \mathrm{l}$ of each primer and $1 \mu \mathrm{l}$ of synthesized cDNA. The final concentrations of primers were $0.2 \mu \mathrm{M}$ (E,S and RdRp gene primers). The thermal cycler was set as per the temperature profile for the Fast PCR assay described earlier.

Sensitivity and specificity of multiplex PCR. The sensitivity of the primer pairs was tested using multiplex PCR with optimized primer pairs for E, S and RdRp gene on archived known SARS-CoV-2 positive and negative samples. Variable $\mathrm{C}_{t}$ values of the samples ranging from 19 to 35 makes it possible to analyze the sensitivity of the primer pairs. Apart from this the template was diluted 10 times serially and tested for sensitivity and specificity of the primer pairs using multiplex PCR.

Cross reactivity analysis. To analyse the cross reactivity of the assay procedure with other respiratory viruses, the multiplex PCR was tested against archived Influenza A positive, Influenza B positive and H1N1positive samples. However, as an efficient alternative cross reactivity studies can be performed in-silico where cross reactivity can be defined as $80 \%$ or more sequence similarity between a primer and any nucleotide sequence in the target $\operatorname{organism}^{13}$.

Multiplex high resolution melting (HRM) coupled real time PCR for detection of SARS-CoV-2. 100 nanogram of previously synthesized cDNA from archived known SARS-CoV-2 positive samples was used with TB Green Premix Ex Taq II (Takara, RR820B) using Rotorgene Q (Qiagen) 5plex Real Time PCR machine following cycling condition of an initial hold at $95{ }^{\circ} \mathrm{C}$ for $5 \mathrm{~min}$; followed by a 45 repeat cycle of hold at $95^{\circ} \mathrm{C}$ for $20 \mathrm{~s}$, annealing at $66^{\circ} \mathrm{C}$ for $30 \mathrm{~s}$, final extension at $72{ }^{\circ} \mathrm{C}$ for $20 \mathrm{~s}$. High Resolution Melt profile was set for a range of temperature from 55 to $95^{\circ} \mathrm{C}$ with $0.1^{\circ}$ gradual increments. Standardized primer pairs were used at a final concentration of $0.2 \mu \mathrm{m}$ for simultaneous detection of $\mathrm{E}, \mathrm{S}$ and RdRP genes in the SARS-CoV-2 genome.

Sequencing and phylogenetic analysis. PCR amplicons of E, S and RdRp gene were sequenced through Sanger sequencing (Bioserve sequencing service from Reprocell USA, inc, Hyderabad, Telangana. India). The obtained sequence was aligned separately for the three different gene targets against the SARS-CoV-2 reference sequence (NC_045512) and other related coronavirus sequences obtained from the NCBI database to analyse the percent identity.

Compliance statement. All the experimental procedures were performed in accordance with the relevant guidelines and regulations provided by Indian Council of Medical Research (ICMR) which is again in accordance with WHO laboratory safety manual related to the novel coronavirus (2019-nCoV) (https://www.who. $\mathrm{int} /$ docs/default-source/coronaviruse/laboratory-biosafety-novel-coronavirus-version-1-1.pdf?sfvrsn=912a9 847_2). All the samples were appropriately processed and maintained in a well-ventilated Biosafety cabinet by personnel with demonstrated capability. All bio hazardous waste generated were disinfected using Sodium Hypochlorite $(0.1 \%)$ for general disinfection and $1 \%$ hypochlorite solution was used for any kind of spillage during sample processing. The entire work was done in the dedicated Biosafety level-3 (BSL-3) facility of State Level Viral Research and Diagnostics Laboratory (VRDL) Gauhati Medical College and Hospital. This study also has the ethical approval of the Institutional Ethical Committee of Gauhati Medical College \& Hospital, Guwahati, Assam-781032 vide ethical approval letter no: MC/190/2007/Pt II/Oct. 2020/14.

Ethical clearance. The study has been ethically approved by the institutional ethical committee of Gauhati Medical College \& Hospital, Guwahati, Assam-781032 vide ethical approval letter no: MC/190/2007/Pt II/Oct. 2020/ 14 .

\section{Results}

Primer optimization. In-silico validation of primer pairs and amplicon sequences showed no secondary structure and the possibility of self or heterodimer formation was not observed. In silico PCR tool nullified the possibility of nonspecific reactions within the same genome as well as genomes from other related species. The optimum annealing temperature of primer pairs was found to be $66^{\circ} \mathrm{C}$. The optimum primer concentration for multiplex PCR was found to be $0.2 \mu \mathrm{M}$ final concentration of each primer. With this primer concentration, the resulting Agarose gel image showed no primer dimer formation (Fig. 1). 

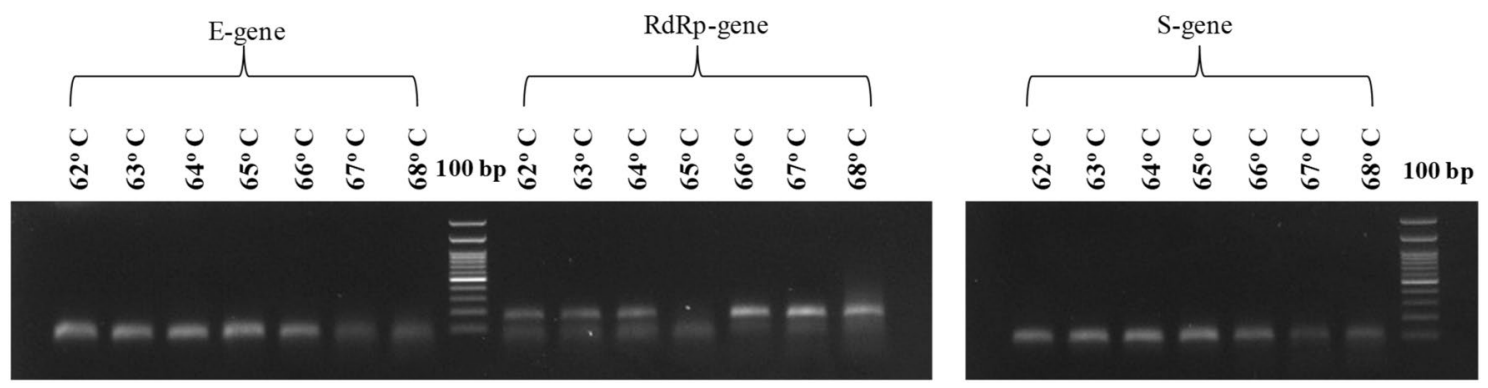

Figure 1. Amplification of E, RdRp and $\mathrm{S}$ genes at different temperature in gradient PCR. (Lane 1-7 E-gene, Lane 8100 bp ladder, Lane 9-15 RdRp-gene, Lane 16-22 S-gene, Lane 23100 bp ladder.

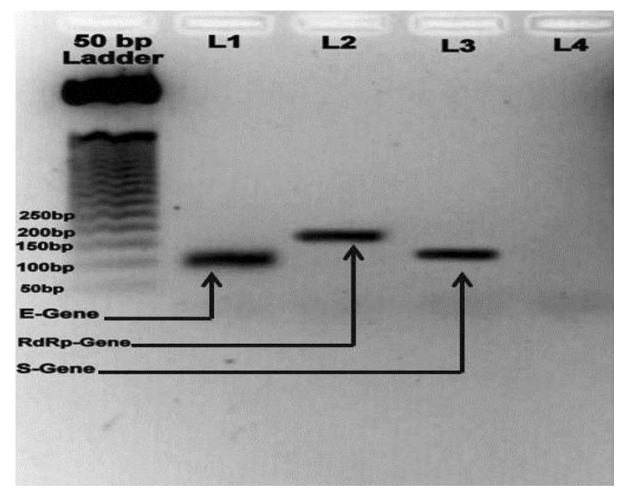

Figure 2. Fast PCR protocol for SARS-CoV-2 detection. Gel electrophoresis results from PCR (35 cycles) showing amplification of RdRp-Gene (Lane-2, L2), S-Gene (Lane-3, L3) and E-gene (Lane-1, L1), and Negative Control (Lane-4, L4) respectively. Ladder used 50 bp DNA ladder (Promega, Cat. No: G4521).

Fast PCR protocol for SARS-CoV-2 detection. Following primer optimization, all three primers were tested separately using a single known positive sample with our optimized PCR cycling condition to observe the amplification efficiency of the protocol. Agarose gel electrophoresis showed distinct band of size $101 \mathrm{bp}, 103 \mathrm{bp}$, and $160 \mathrm{bp}$ for E gene, $\mathrm{S}$ gene and RdRp gene respectively without any primer dimer formation (Fig. 2).

Development of a fast multiplex PCR protocol for SARS-CoV-2 detection. We developed a Fast PCR protocol for SARS-CoV-2 detection and easy implementation in any biological laboratory in the world. Archived positive samples from State Level Viral Research and Diagnostics Laboratory (VRDL) Gauhati Medical College and Hospital was used for cDNA preparations and used as a template for multiplex PCR optimization. The PCR was performed for 35 cycles following the cycling conditions described earlier. The gel electrophoresis showed two sharp bands of variable size i.e. $160 \mathrm{bp}$ for the targeted RdRp gene and another of two overlapping bands of $101 \mathrm{bp}$ and $103 \mathrm{bp}$ for the E gene and S gene of SARS-CoV-2 respectively (Fig. 3).

HRM coupled multiplex RT-PCR based detection of SARS-CoV-2. As an alternative to our Fast Multiplex PCR protocol for SARS-CoV-2 detection, we further developed a multiplex RT PCR assay with implementation of High-Resolution Melting profile in addition to the thermal cycling profile for obtaining an enhanced separation of melt curve. A very similar result was obtained for HRM coupled multiplex RT PCR assay. The amplification plot showed one combined reaction curve with significantly lower $C_{t}$ value for all the three primers put together apart from the amplification curve for the individual primer put in separate reaction tube (Fig. 4). The accuracy of the multiplex reaction in real time was confirmed further by analyzing the highresolution melt curve with three distinct peaks (Fig. 5) which were further compared with the melt curve peak obtained for the three primers when used separately in distinct tubes (Figs. 6, 7, 8, 9). Based on these observations we can conclude that the three distinct melt curve peaks were of $\mathrm{E}, \mathrm{S}$ and RdRp genes. Thus, this result demonstrates that the newly developed HRM coupled multiplex RT PCR protocol can be used for the fast and accurate detection of SARS-CoV-2 without the need of a costly probe based approach of detection.

Sensitivity and specificity. The multiplex RT PCR assay successfully amplified all the three targets with distinct melt curve (E, S and RdRp gene) without any false results upon testing with known positive archived samples of SARS-CoV-2 having $C_{t}$ values ranging from 19 to 35 obtained with other commercial kits. A $C_{t}$ value $<30$ was obtained for $\mathrm{N}=100(100 \%)$ archived SARS-CoV-2 positive sample inclusive of different age and 


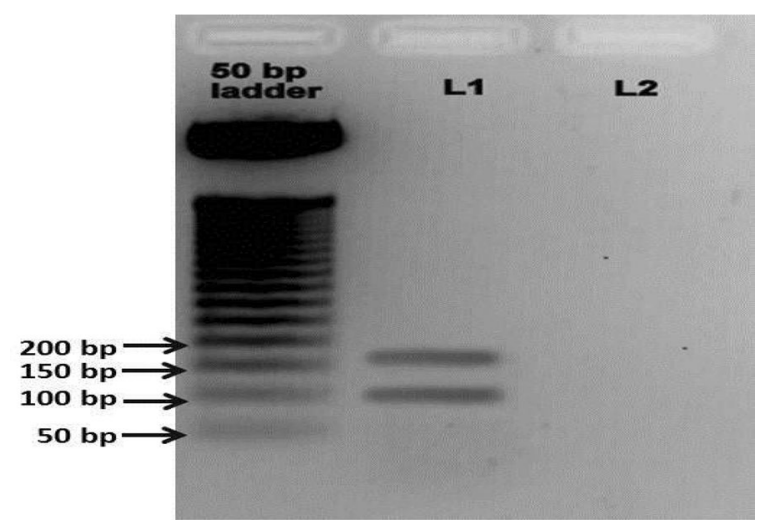

Figure 3. Fast Multiplex PCR protocol for SARS-CoV-2 detection: gel electrophoresis results obtained from multiplex PCR in the SARS-CoV-2, showing amplification of two genes (RdRp Gene and E gene) Since E gene and S gene product are overlapping. Ladder used 50 bp DNA ladder (Promega, Cat. No: G4521).

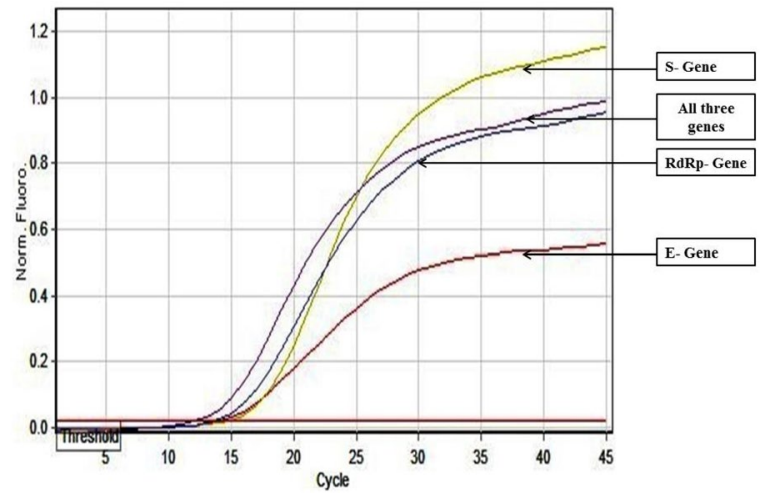

Figure 4. Amplification graph of $\mathrm{E}, \mathrm{S}$ and RdRp gene of SARS-CoV-2 using SYBR green master mix (TB Green Premix Ex Taq II, Takara, Cat. No: RR820B). All the three primers were tested individually as well as in multiplexing reaction in single tube. Amplification plot showed efficient amplification of the three gene individually and also upon multiplexing of the three primers.

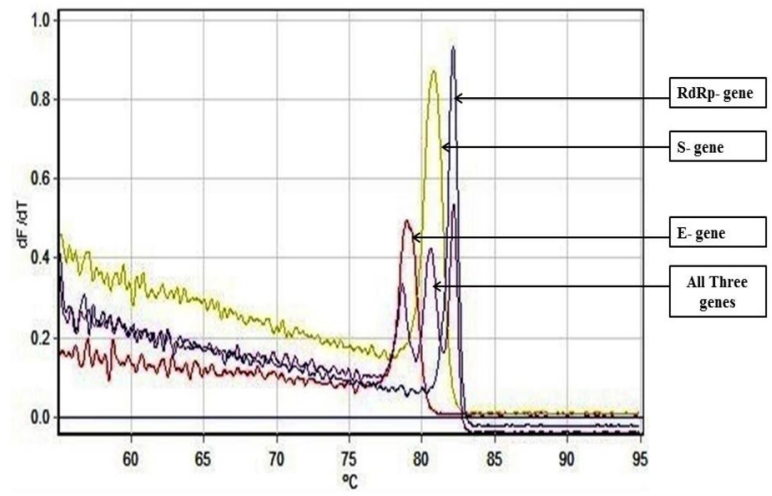

Figure 5. High Resolution Melting Curve plot for the amplicons of E, S and RdRp gene. All the three amplicons showed distinct well separated melting peak both in multiplexing reaction and in individual reaction condition.

gender. This is comparable with the recommended maximum $C_{t}$ value for positive interpretation of COVID-19 using commercially available approved RT-PCR based detection kit $\left(\mathrm{C}_{\mathrm{t}} \leq 35\right)$, and as such the number of true positive (TP) sample was obtained as $100(100 \%)$ and the number of true negative (TN) sample was $33(100 \%)$ without any false result. Thus the sensitivity and specificity was obtained as Sensitivity $=T P /(T P+F N)=100 /$ 


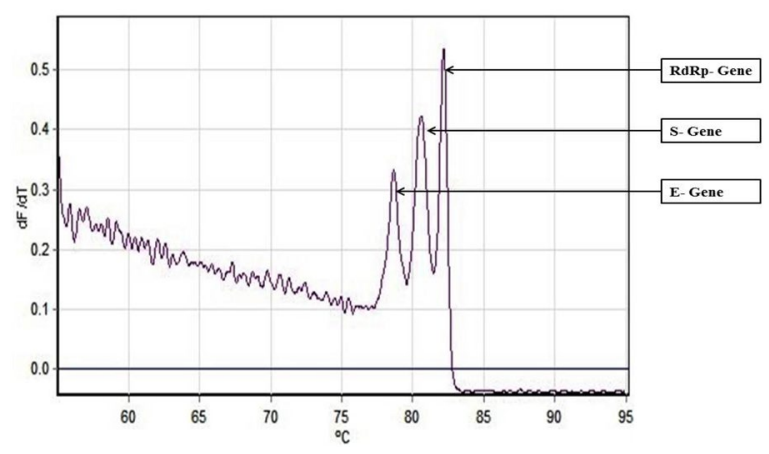

Figure 6. Well separated melt curve peak for E, S and RdRp gene upon multiplex RT-PCR.

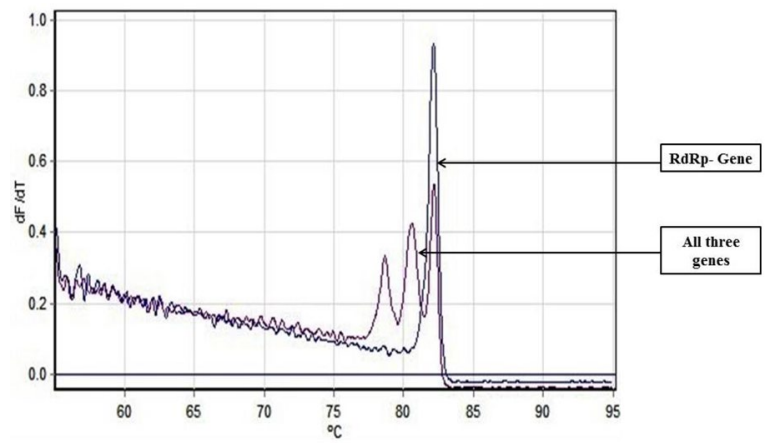

Figure 7. Individual melt curve peak for RdRp gene obtained upon single-plex RT-PCR reaction using primer pairs for RdRp gene.

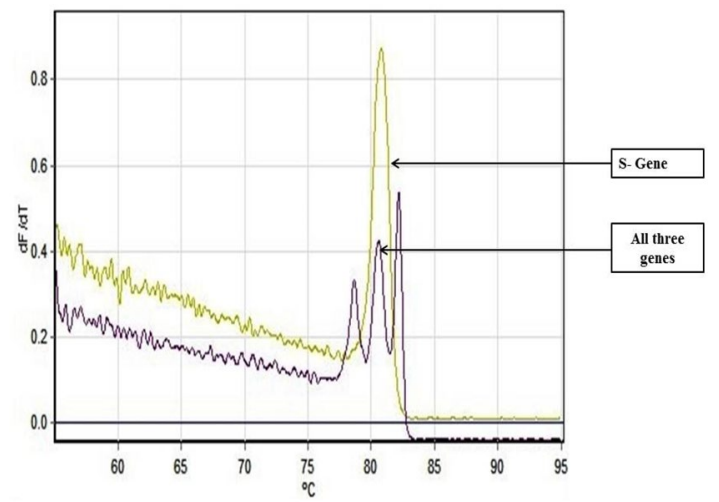

Figure 8. Individual melt curve peak for $S$ gene obtained upon single-plex RT-PCR reaction using primer pairs for $S$ gene.

$(100+0)=1$ and Specificity $=T N /(T N+F P)=33 /(33+0)=1$. This is suggestive of the enhanced sensitivity of the HRM coupled multiplex RT PCR assay.

Cross reactivity of the assay. There were no false positive results from any of the primer pairs for the three target genes when the cross reactivity of the assay procedure was analysed with archived Influenza A, Influenza B and H1N1 positive samples. In-silico cross reactivity analysis for all the three primer pairs further showed $100 \%$ SARS-CoV-2 specific hit ${ }^{14-16}$.

Limit of detection (LoD). LoD was determined by using a tenfold serial dilution of the clinical sample SC005G $\left(4.71 \times 10^{5} \mathrm{RNA}\right.$ copies $\left./ \mathrm{ml}\right)$, which was previously reported to have a low $\mathrm{C}_{\mathrm{t}}$ value $\left(C_{t^{-}}\right.$ORF1b $=19, C_{t^{-}} \mathrm{Ngene}=21$; Meril COVID-19 detection kit). All the dilutions were replicated 5 times and the average $\mathrm{C}_{\mathrm{t}}$ value obtained for individual target region for each dilution has been shown in Table 1 All the three targets were detected in 100\% 


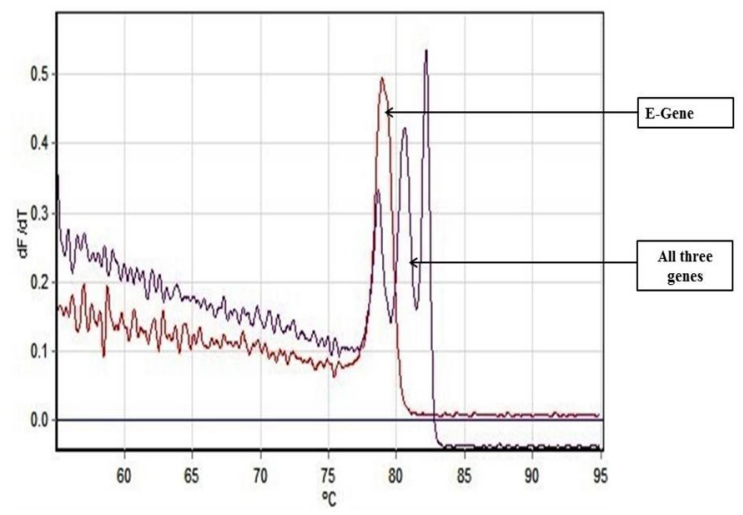

Figure 9. Individual melt curve peak for E gene obtained upon single-plex RT-PCR reaction using primer pairs for E gene.

\begin{tabular}{|c|c|c|c|c|c|c|c|c|c|}
\hline \multicolumn{4}{|c|}{ Target 1 (RdRp) } & \multicolumn{3}{|l|}{ Target 2 (E-gene) } & \multicolumn{3}{|l|}{ Target 3 (S-gene) } \\
\hline Dilutions & Replicates detected & Average CT-values & SD & Replicates detected & Average CT-values & SD & Replicates detected & Average CT-values & SD \\
\hline $10^{-1}$ & $5 / 5(100 \%)$ & 22.87 & 0.553968 & $5 / 5(100 \%)$ & 23.67 & 0.915341 & $5 / 5(100 \%)$ & 24.25 & 0.604276 \\
\hline $10^{-2}$ & $5 / 5(100 \%)$ & 25.77 & 0.663928 & $5 / 5(100 \%)$ & 26.22 & 0.663099 & $5 / 5(100 \%)$ & 27.62 & 0.934532 \\
\hline $10^{-3}$ & $5 / 5(100 \%)$ & 26.62 & 0.703314 & $5 / 5(100 \%)$ & 27.92 & 0.557692 & $5 / 5(100 \%)$ & 28.43 & 0.79117 \\
\hline $10^{-4}$ & $5 / 5(100 \%)$ & 31.42 & 1.406722 & $5 / 5(100 \%)$ & 32.58 & 0.978673 & $5 / 5(100 \%)$ & 33.45 & 0.41142 \\
\hline $10^{-5}$ & $5 / 5(100 \%)$ & 34.28 & 0.407799 & $5 / 5(100 \%)$ & 33.77 & 0.721249 & $5 / 5(100 \%)$ & 34.30 & 0.44238 \\
\hline $10^{-6}$ & $2 / 5(40 \%)$ & 37.42 & 1.286934 & $2 / 5(40 \%)$ & 38.21 & 0.59397 & $3 / 5(60 \%)$ & 39.53 & 0.600083 \\
\hline $10^{-7}$ & $0 / 5(0 \%)$ & - & - & $0 / 5(0 \%)$ & - & - & $0 / 5(0 \%)$ & - & - \\
\hline
\end{tabular}

Table 1. Average $\mathrm{C}_{\mathrm{t}}$ values obtained for three target regions from a series of 7 tenfold serial dilution of a clinical specimen previously detected SARS-CoV-2 positive (SC005G) using Meril covid-19 detection kit.

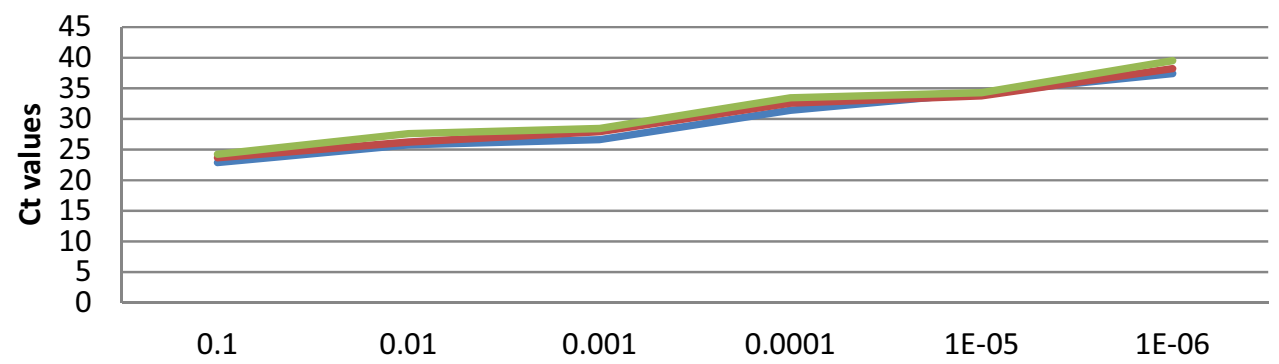

\section{Dilution (10 fold serial dilution)}

Target $1 \quad$ Target $2 \quad$ Target 3

Figure 10. Graph showing average $C_{t}$ value obtained from five replicates for a series of 7 , tenfold serial dilution of an initially tested SARS-CoV-2 positive sample. All replicates were detected up to $10^{-5}$ dilution. No replicates were detected at $10^{-7}$ dilution.

of the replicates for dilution ranging from $10^{-1}\left(4.71 \times 10^{4} \mathrm{RNA}\right.$ copies $\left./ \mathrm{ml}\right)$ to $10^{-5}(4.71 \mathrm{RNA}$ copies $/ \mathrm{ml})$ with a corresponding average $C_{t}$ value of 34.28 for RdRp gene, $C_{t}$ value of 33.77 for E gene, and $C_{t}$ value of 34.30 for $S$ gene (Fig. 10). At $10^{-6}$ dilution, Target 1 and Target 2 were detected in $40 \%$ of the replicates with average $C_{t}$ value of 37.42 for Target 1 (RdRp gene) and 38.21 for Target 2 (E-gene). Target 3 (S-gene) was detected in $60 \%$ of replicates with average $C_{t}$ value of 39.53 as shown in Table 1 . However, none of the target was detected in any of the replicates for $10^{-7}$ dilution (Table 1 ).

Experimental $C_{t}$ values obtained for target 1, 2 and 3 among the positive specimens. All the 100-specimen showed reportable $C_{t}$ values for all the three targets. Mean $C_{t}$ value for Target 2 was found to be lowest among the tested SARS-CoV-2 positive samples followed by Target 1 and Target 3 . However considerable degree of similarity and closeness of $\mathrm{C}_{\mathrm{t}}$ values among the three targets were observed. When stratified by age, within age 


\begin{tabular}{|l|l|l|l|l|}
\hline \multirow{2}{*}{ Group } & \multirow{2}{*}{ No of specimen } & Target 1(RdRp gene) & Target 2 (E gene) & Target 3 (S gene) \\
\cline { 3 - 5 } & Mean $\mathrm{C}_{\mathrm{t}}$ & Mean $\mathrm{C}_{\mathrm{t}}$ & Mean $\mathrm{C}_{\mathrm{t}}$ \\
\hline All specimen & 100 & 24.53 & 23.96 & 25.37 \\
\hline Age $<10 \mathrm{y}$ & $2(2 \%)$ & 22.56 & 24.05 & 25.76 \\
\hline Age $10-19 \mathrm{y}$ & $2(2 \%)$ & 25.7 & 24 & 25.7 \\
\hline Age $20-29 \mathrm{y}$ & $4(4 \%)$ & 26.50 & 26 & 25.7 \\
\hline Age $30-39$ y & $7(7 \%)$ & 23.3 & 23 & 23.8 \\
\hline Age $40-49$ y & $10(10 \%)$ & 26.3 & 25.7 & 27.4 \\
\hline Age $50-59$ y & $31(31 \%)$ & 24.79 & 24.2 & 25.5 \\
\hline Age $60-69$ y & $29(29 \%)$ & 24.74 & 24.4 & 25.9 \\
\hline Age $70-79$ y & $11(11 \%)$ & 23.1 & 21.9 & 24.01 \\
\hline Age $80-89$ y & $4(4 \%)$ & 19.55 & 18.9 & 21 \\
\hline Age $>89$ y & 0 & 0 & 0 & 0 \\
\hline
\end{tabular}

Table 2. Mean $\mathrm{C}_{\mathrm{t}}$ values obtained for the entire three targets among the positive specimens, stratified by age. Age group 80-89 showed considerably lower $C_{t}$ value for the entire three targets in comparison to mean $C_{t}$ which is representative of high viral load.

group 80-89 years, the $C_{t}$ value for, Target 1 was $4.98 C_{t}$ lower than the overall mean $C_{t}$ for Target 1 , for Target 2 it was $5.06 \mathrm{C}_{t}$ lower and for Target 3 it was found to be $4.37 \mathrm{C}_{t}$, lower than the overall $\mathrm{C}_{\mathrm{t}}$ value (Table 2) (Supplement Figure 1), which is a representative of high viral load in this age group.

Comparison of sensitivity and specificity of our In house RT-PCR assay.

(a) Comparison of $\mathrm{C}_{\mathrm{t}}$ value

The sensitivity and specificity of the primer pairs were further analysed by comparing the $\mathrm{C}_{\mathrm{t}}$ value obtained through our optimized detection protocol with the $C_{t}$ value obtained for the same set of samples $(N=100)$ using commercially available detection kits used in diagnostic setup (Meril COVID-19 One-Step RT-PCR Kit; Cat no: NCVPCR-02). The average $C_{t}$ value was found to be $\leq 30$ for all the three target (Supplement Table 1) which is comparable with the Meril COVID-19 RT-PCR kit $\left(\mathrm{C}_{t}\right.$ value $\leq 35$, positive) with significantly reduced median $\mathrm{C}_{\mathrm{t}}$ value obtained with our In house HRM coupled RT-PCR assay (Fig. 11).

\section{(b) Comparison of limit of detection (LoD)}

Upon analysing the Limit of Detection (LoD) for Meril COVID-19 RT-PCR kit using the same serially diluted sample, efficient amplification of the prescribed target Orf $1 \mathrm{~b}$ and $\mathrm{N}$ gene was obtained for the dilution range from $10^{-1}$ to $10^{-3}$ with $\mathrm{C}_{\mathrm{t}}$ value $\leq 35$ for both the target. As such the limit of detection was found to be 471 RNA copies/ml (Fig. 12). Although amplification was observed for further diluted sample $\left(10^{-4}\right.$ to $\left.10^{-6}\right)$ but the $\mathrm{C}_{\mathrm{t}}$ value obtained followed a gradual increase pattern from the recommended $\mathrm{C}_{\mathrm{t}}$ value for interpretation of SARS-CoV-2 positive detection (Supplement Table 2). No amplification was observed at $10^{-7}$ dilution. However efficient amplification up to $10^{-5}$ dilution (approximately 5 RNA copies per reaction, $\mathrm{C}_{\mathrm{t}}$ value $<35$ ) using our In house RT-PCR assay is suggestive of enhanced limit of detection of the assay.

Risk of appearing false-negative result in the assay. Our tenfold serial dilution study showed the assay LoD to be $10^{-5}$ dilution (4.71 RNA copies) with corresponding $C_{t}$ value of 34.28 for Target $1,33.72$ for Target 2 , and 34.3 for Target 3 . At $10^{-1}$ dilution $100 \%$ of the specimens were detected for the entire three targets. As such, the risk of false negative result increases from $0 \%$ at $10^{-1}$ dilution (approximately $11 \mathrm{C}_{\mathrm{t}}$ lower than LoD) to $95 \%$ at LoD, which increases further with increase in $\mathrm{C}_{t}$ value after LoD. In the studied cohort of SARS-CoV-2 positive samples Mean $C_{t}$ value for Target 1(24.53) and Target 2 (23.96) was $10 C_{t}$ below the LoD, and for Target 3, mean $C_{t}(25.37)$ value was $9 C_{t}$ lower than the LoD value. Only $2 / 100(2 \%)$ positive samples showed a slightly higher $\mathrm{C}_{\mathrm{t}}$ value only for Target 3 (approx. 35) than the LoD, whereas for Target 1 and 2 , the obtained $\mathrm{C}_{\mathrm{t}}$ values were near the assayed LoD, and as such would be at risk of false negative result. However, the assay efficiently detects 98/100 (98\%) samples for Target 1 and Target 2, thereby supporting the enhanced sensitivity for RdRp gene (Target 1) and E gene (Target 2) detection (Fig. 13).

The time required for the assay. The extraction of RNA from the sample will depend upon the type of kit or protocol used. Most of the commercially available kit requires around 35-45 min for RNA extraction. In the present study, following the RNA extraction, cDNA synthesis required $45 \mathrm{~min}$ with the Tetro cDNA synthesis kit (Meridian Bioscience, BIO-65043) followed by PCR amplification of the target genes from SARS-CoV-2 which required $37 \mathrm{~min}$. Subsequently Agarose gel-based visualization needed approximately $30 \mathrm{~min}$. Thus, the Fast 


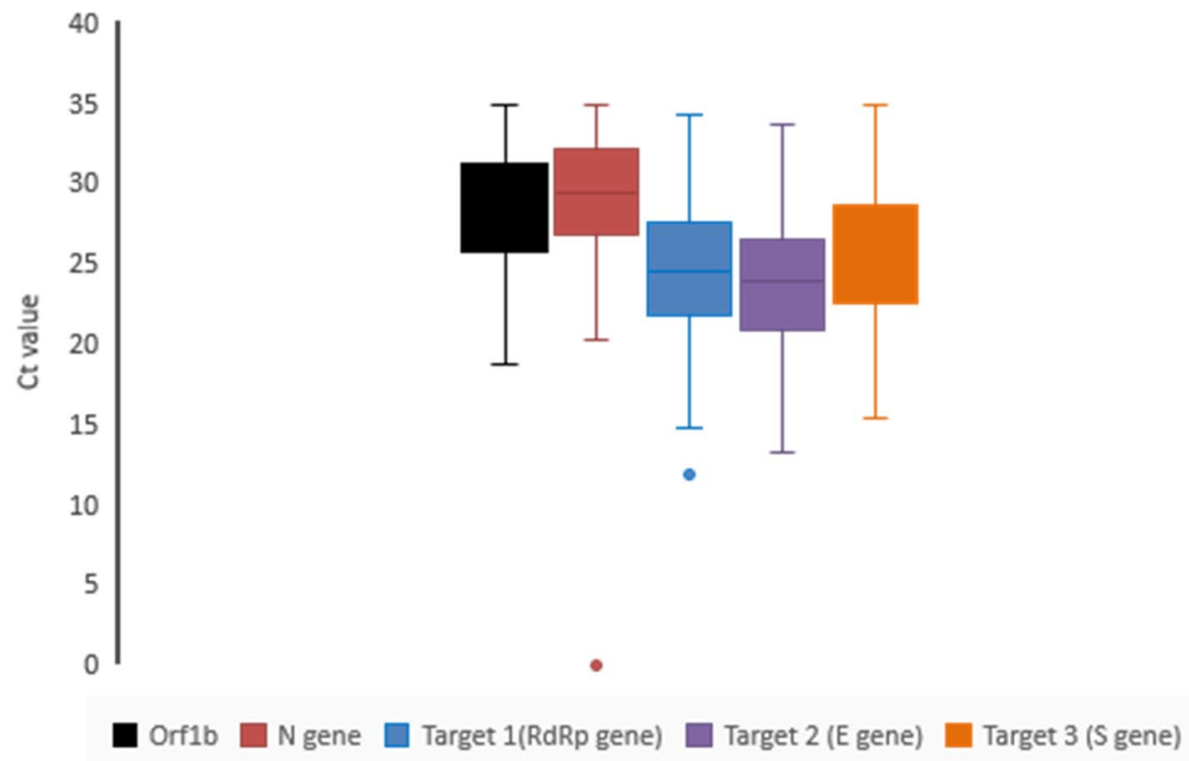

Figure 11. Box plot diagrams representing the $C_{t}$ values obtained for $N=100$ samples previously tested SARSCoV-2 positive with Meril Covid-19 detection kit. Dark bar: median; box: 25-75\% interquartile; whiskers and dots: range in the box plot. Significant difference in $\mathrm{C}_{\mathrm{t}}$ values was observed upon testing with In house SARSCoV-2 detection assay (Target 1, Target 2 and Target 3) when compared with that of Meril Covid-19 detection kit (Orflb and N gene). Enhanced sensitivity of the in-house RT-PCR assay is evident from the plot showing comparable reduction in median $\mathrm{C}_{\mathrm{t}}$ value.

\section{Comparision of average $C_{t}$ value obtained at different dilution with In house RT-PCR assay and Meril Covid-19 RT-PCR kit}

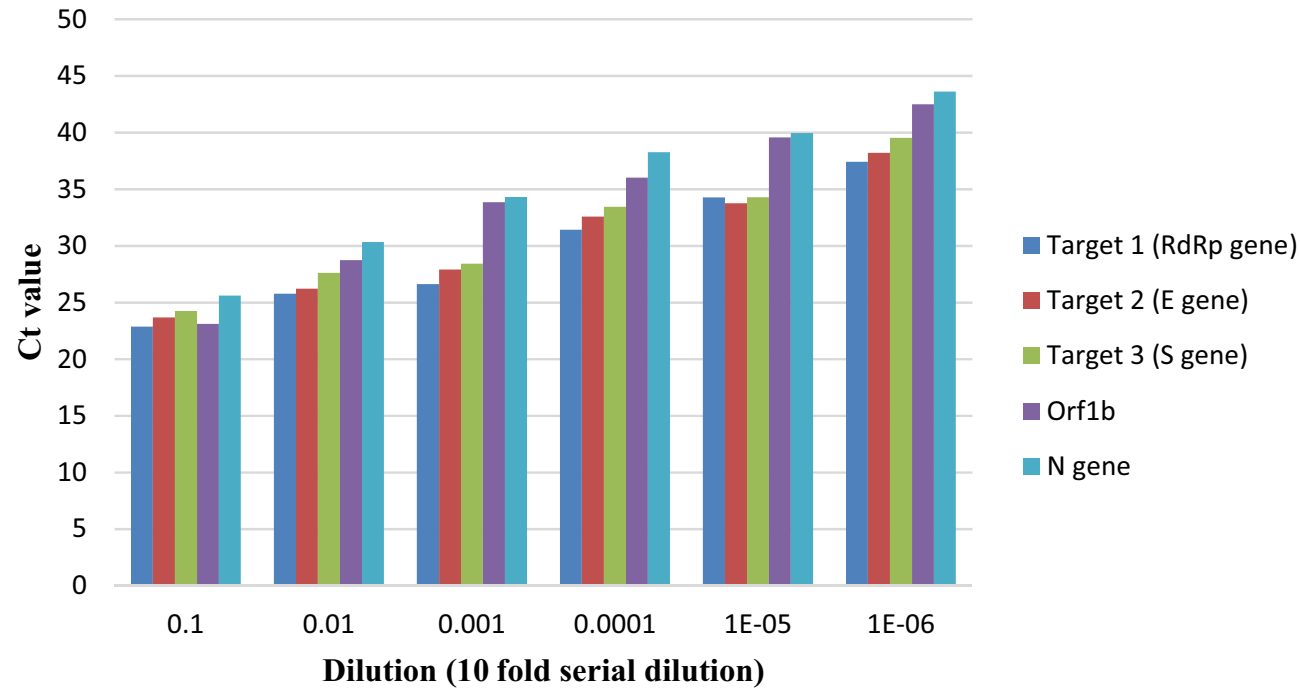

Figure 12. Comparision of average $C_{t}$ value obtained at different dilution (tenfold serially diluted) with In house RT-PCR assay and Meril COVID-19 RT-PCR kit. Although efficient amplification was obtained upto $10^{-6}$ dilution with both the assay, $\mathrm{C}_{\mathrm{t}}$ value $\geq 35$.

PCR assay protocol needed 67 min after RNA extraction and cDNA synthesis. With the HRM coupled multiplex RT-PCR based detection, a time of 96 min was needed post RNA extraction and cDNA synthesis. 


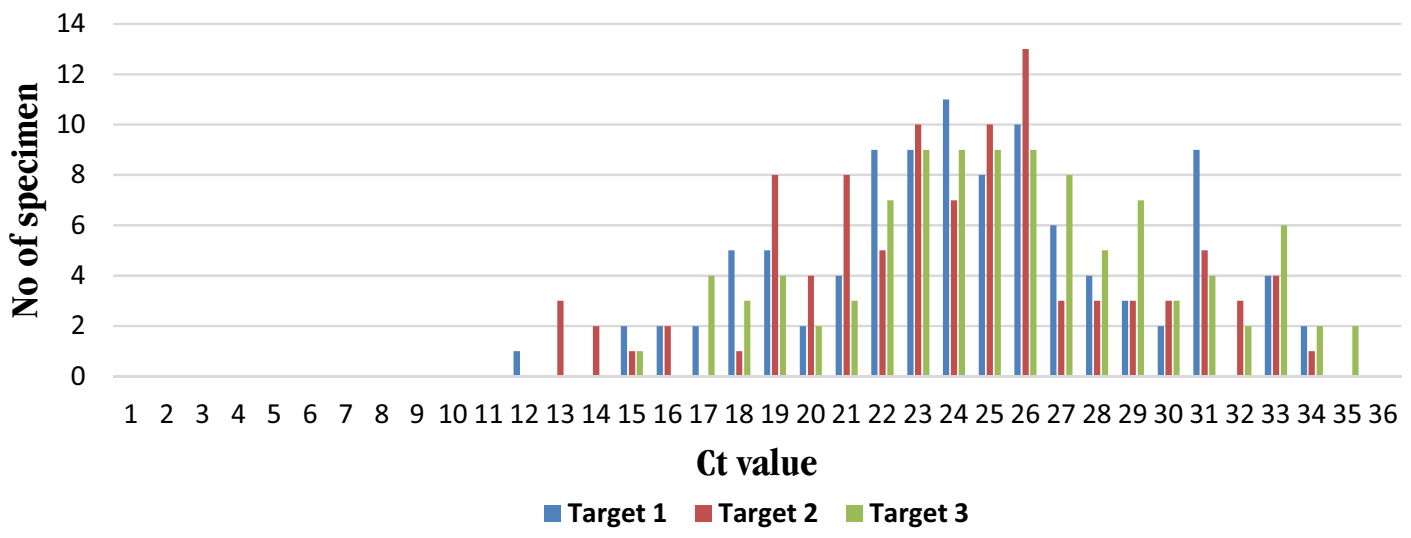

Figure 13. Distribution of experimentally obtained $C_{t}$ values for the 100 positive specimen for Target 1 , Target 2 , and Target 3 are plotted. Only 2/100 (2\%) positive sample were found with $\mathrm{C}_{t}$ values slightly higher than LoD or near the assay LoD and as such the sensitivity of detection may be less than $100 \%$. Remaining 98 specimens showed efficient detection of the entire three targets.

\section{Discussion}

Targeting the nucleic acid evaluation of any living microbial entities is considered the gold standard for the detection of any active infection. The advantage of PCR-based viral detection relies on high reproducibility, sensitivity and ability to quantify vial load with accuracy ${ }^{9}$. In the present study, we developed three sets of primers encompassing the E gene, RdRp gene and S gene of the SARS-CoV-2 genome with enhanced sensitivity and specificity. The primers sets were designed with the additional objective of extended feasibility to further amplify in both gel-based multiplex PCR assay and SYBR green based real-time detection in a single tube. The same sets of primer produced distinct amplification in both conventional as well as HRM coupled multiplex RT-PCR based detection assay. Indeed, with optimized primer concentration and low template concentration, this study seems to provide a cost-effective detection protocol with accuracy, which opens up prospective vistas to develop and commercialize a new detection kit. However, developing a fast-track detection kit from our study protocol needs further research with absolute refinement and necessary modification. Owing to its highly sensitive primer pairs, the assay procedure offers versatility in its application in variable resource settings for efficient and costeffective detection of SARS-CoV-2. Such an innovative approach can additionally set a significant impact on the detection and management of the COVID-19 pandemic and is useful to prepare for the future onset of any acute viral infection of similar nature and magnitude.

The present study has shown promising results in the cross-reactivity assay and Limit of Detection (LoD) analysis. Non-amplification of our targeted genes in Influenza A, Influenza B and H1N1 positive samples further reduces the chance of cross-contamination and diminished the risk of getting false-positive results. Moreover, LoD analysis of the samples up to $10^{-5}$ dilution with $100 \%$ efficacy revealed high specificity of the primers even in low template concentration (approximately 5 RNA copies per reaction $\left(C_{t}\right.$ value $\left.<35\right)$ provides added advantages besides exhibiting an obvious comparison with other published assay. Supportive evidence came from the study of Garg et al. ${ }^{17}$ which reports that Fosun COVID-19 RT-PCR kit have the lowest LoD (300 Copies/ml, $\left.\mathrm{C}_{\mathrm{t}}<36\right)$ among the seven RT-PCR kit evaluated in the study. However, the efficacy of the reaction reduces considerably in $10^{-6}$ dilution may be due to exhausting template concentration. Further obtaining a $C_{t}$ value $\leq 30$ for all the three target in $(\mathrm{N}=100)$ archived positive sample without any false result with our in-house RT-PCR assay is suggestive of its enhanced sensitivity and specificity. Significant variation in the $C_{t}$ values was observed from the original sample $\mathrm{C}_{t}$ value derived from COVID-19 positive cases, which indicates the possibility of having varied specificity of the original SARS-CoV-2 detection kit (Meril COVID-19 detection kit, $\mathrm{C}_{\mathrm{t}} \leq 35$, positive)). The penultimate evaluation of the study has been established due to reportable and reproducible $C_{t}$ value that extensively justified our study design. Highest deviation of $\mathrm{C}_{t}$ was observed in the segregated age group of 80-89 years from mean $\mathrm{C}_{\mathrm{t}}$ value of the three target genes by about 4-5 unit, that might be due to pipetting error or sample handling error during experiment setup.

Initially approved SARS-CoV-2 RT-PCR test kit developed by various manufacturers around the world targeted the different number of genes, embedding three and two or even single gene with or without internal control. Accordingly, a diverse range of cost, specificity and efficacy of the kits were observed. For instance, Gene Matrix (USA), Daan Gene Co. Ltd (China), Kogene Biotech (Korea), LabGenomics (South Korea), Primer Design (UK), SansureBiotechInc. (China) used either combination of N, RdRP or E, RdRP or ORF1ab, N probe/primer in the kit ${ }^{18,19}$. However, all the RT-PCR based kit possess limitation in terms of cost of reagent, reporter dye and synthesis of high-end specificity probe. The cost of the probe-based RT-PCR test is an obligatory limiting factor of COVID-19 management that lay a huge financial burden for any resource-limited country in the world ${ }^{13}$. For most of the presently available RT-PCR assay kits, the estimated cost is around \$ 40-50 (Centres for Medicare and Medicaid Services, COVID-19 test pricing. 2020) ${ }^{14}$. Moreover, some detection assays possess constraints both in terms of reagent limitation and low specificity with initial template concentration. Apart from that, whether constant mutation of the SARS-CoV-2 genome is influencing the efficacy of probe-based detection is still not revealed entirely and that needs profound research. However, our detection assay involving the implementation 
of high-resolution melting analysis following multiplex PCR amplification using SYBR green master mix further reduces the cost significantly by eliminating the need for probe, and cut down the cost to around \$13-15.

The first recommended detection kit in India was developed and supplied by the National Institute of Virology (NIV), Pune, which used the SuperScript III One-Step RT-PCR System with Platinum Taq DNA Polymerase (make Invitrogen Catalogue number: 12574026) that requires about 5-6 h for confirmation of the result. While various other commercial kits are available that target major genes of SARS-CoV-2 requires a time of around 1.0 to $3.5 \mathrm{~h}$ after sample preparation. In contrast, our protocol observed successful amplification in $37 \mathrm{~min}$ using Fast multiplex PCR and 96 min in HRM coupled real-time detection using SYBR green that reduces the time by around 2-threefold. Additionally, the sample pooling strategy can further contribute to a reduction of cost. In addition to that, sample pooling strategy can further reduce the cost per sample in an emergency ${ }^{20}$. However, this approach requires robust standardization as the probability of reducing efficacy due to the exhaustive PCR component seems to be a major limitation associated with the experiment strategy. With the demonstration of absolute reproducible results with our detection assay involving innovative modification of conventional SARSCoV-2 test protocol, the HRM coupled multiplex RT-PCR assay represents an easy, fast and low-cost option for SARS-CoV-2 detection with resource limitation.

Received: 10 April 2021; Accepted: 13 August 2021

Published online: 09 September 2021

\section{References}

1. Chan, J. F. W. et al. Improved molecular diagnosis of COVID-19 by the novel, highly sensitive and specific COVID-19-RdRp/Hel real-time reverse transcription-PCR assay validated in vitro and with clinical specimens. J. Clin. Microbiol. 58(5), e00310-e320 (2020).

2. Adhikari, S. P. et al. Epidemiology, causes, clinical manifestation and diagnosis, prevention and control of coronavirus disease (COVID-19) during the early outbreak period: a scoping review. Infect. Dis. Poverty 9, 29 (2020).

3. Zhu, N. et al. A novel coronavirus from patients with pneumonia in China. N. Engl. J. Med. 382(8), 727-733 (2020).

4. Holshue, M. L. et al. First case of 2019 novel coronavirus in the United States. N. Engl. J. Med. 382(10), 929-936 (2020).

5. Su, S. et al. Epidemiology, genetic recombination, and pathogenesis of coronaviruses. Trends Microbiol. 24(6), 490-502 (2016).

6. Lu, R. et al. Genomic characterisation and epidemiology of 2019 novel coronavirus: implications for virus origins and receptor binding. Lancet 395(10224), 565-574 (2020).

7. Cascella, M., Rajnik, M., Cuomo, A., Dulebohn, S. C. \& Di Napoli, R. Features, evaluation and treatment coronavirus (COVID-19) (StatPearls Publishing, 2020).

8. Yuen, K. S., Ye, Z. W., Fung, S. Y., Chan, C. P. \& Jin, D. Y. SARS-CoV-2 and COVID-19: the most important research questions. Cell Biosci. 10, 40 (2020).

9. Watzinger, F., Ebner, K. \& Lion, T. Detection and monitoring of virus infections by real-time PCR. Mol. Asp. Med. 27(2-3), 254-298 (2006).

10. Vogels, C. B. F. et al. Analytical sensitivity and efficiency comparisons of SARS-CoV-2 RT-qPCR primer-probe sets. Nat. Microbiol. 5(10), 1299-1305 (2020).

11. Nalla, A. K. Comparative performance of SARS-CoV-2 detection assays using seven different primer-probe sets and one assay kit. J. Clin. Microbiol. 58(6), e00557-e620 (2020).

12. Chan, J. F. W. et al. A familial cluster of pneumonia associated with the 2019 novel coronavirus indicating person-to-person transmission: a study of a family cluster. Lancet 395(10223), 514-523 (2020).

13. Afzal, A. Molecular diagnostic technologies for COVID-19: Limitations and challenges. J. Adv. Res. 26, 149-159 (2020).

14. Centers for Medicare and Medicaid Services. Medicare administrative contractor (MAC) COVID-19 test pricing. 2020. https:// www.cms.gov/files/document/maccovid-19-test-pricing.pdf. Accessed 21 May 2020.

15. Corman, V. M. et al. Detection of 2019 novel coronavirus (2019-ncov) by real-time rt-pcr. Eurosurveill. Bull. Eur. Mal. Transmissibles Eur. Commun. Dis. Bull. 25, 2000045 (2020).

16. Lu, X. et al. Us cdc real-time reverse transcription pcr panel for detection of severe acute respiratory syndrome coronavirus 2. Emerg. Infect. Dis. 26, 1654 (2020).

17. Garg, A. et al. Evaluation of seven commercial RT-PCR kits for COVID-19 testing in pooled clinical specimens. J. Med. Virol. 93(4), 2281-2286 (2021).

18. Das, P. et al. COVID diagnostics by molecular methods: A systematic review of nucleic acid based testing systems. Indian J. Med. Microbiol. 39(3), 271-278 (2021).

19. Martínez-Murcia A, et al. In silico analysis of rt-qpcr designs recommended by who for detection of 2 sars-cov- 2 and a commercial kit validated following une/en iso 17025:2005 and 3 two reference laboratories. BioRxiv (2020).

20. Chandrashekar, S. Half a decade of mini-pool nucleic acid testing: Cost-effective way for improving blood safety in India. Asian J. Transfus. Sci. 8(1), 35-38 (2014).

\section{Acknowledgements}

The author acknowledges the Department of Health Research Government of India for financial support. The authors also thank Viral Research and Diagnostics Laboratory (VRDL), Department of Microbiology, Gauhati Medical College for providing a laboratory facility to perform the study and the Department of Bioengineering \& Technology, Gauhati University for overall support. The authors also acknowledges Mr Himangka Kaushik for english editing in the manuscript.

\section{Author contributions}

M.J.K. and P.P.D. wrote the Manuscript.M.J.K. and K.D. contributed equally to design the work plan including methodology and primers to be used.R.D. and P.P. DAS perform all the molecular wet lab work at Gauhati Medical college \& hospital.S.K. and G.H. prepared the tables and figures.All authors reviewed the manuscript.

\section{Funding}

This study was financially supported by the Department of Health Research Government of India vide Sanction Number R.12016/01/2017-HR dated: 20/02/2018. 


\section{Competing interests}

The authors declare no competing interests.

\section{Additional information}

Supplementary Information The online version contains supplementary material available at https://doi.org/ 10.1038/s41598-021-97502-1.

Correspondence and requests for materials should be addressed to A.S. or S.M.

Reprints and permissions information is available at www.nature.com/reprints.

Publisher's note Springer Nature remains neutral with regard to jurisdictional claims in published maps and institutional affiliations.

(c) (1) Open Access This article is licensed under a Creative Commons Attribution 4.0 International License, which permits use, sharing, adaptation, distribution and reproduction in any medium or format, as long as you give appropriate credit to the original author(s) and the source, provide a link to the Creative Commons licence, and indicate if changes were made. The images or other third party material in this article are included in the article's Creative Commons licence, unless indicated otherwise in a credit line to the material. If material is not included in the article's Creative Commons licence and your intended use is not permitted by statutory regulation or exceeds the permitted use, you will need to obtain permission directly from the copyright holder. To view a copy of this licence, visit http://creativecommons.org/licenses/by/4.0/.

(C) The Author(s) 2021 